\title{
Por una lectura filosófica del texto bíblico
}

\author{
Marc de Launay
}

Muchos filósofos se han confrontado con la Biblia y comentaron textos bíblicos, la mayor parte del tiempo sin precaución filológica. Cuanto más se afirmó la tradición filosófica al emanciparse de la tutela teológica menos se inclinó por reconocer alguna deuda intelectual con respecto a la Biblia. Ahora bien, la irrupción del texto bíblico fue un momento crucial en la historia cultural occidental en la medida en que marca el pasaje de una "forma simbólica" (que Cassirer denomina "mito") a otra ("religión") llevado a cabo por un lenguaje desde entonces desubstancializado; además, el texto bíblico del Pentateuco se esfuerza por destacar una nueva forma de relación con el tiempo: la de la historia, que no es ni cíclica ni tampoco profética, de la que la filosofía hereda sin reconocer, sin embargo, su verdadera deuda.

Palabras clave: forma simbólica, historia "abierta", hermenéutica crítica, relato mítico, deuda filosófica.

Many philosophers have been confronted with the Bible and commented biblical texts, most of the time without any philological precautions. The more a philosophical tradition asserted itself liberated from its theological supervision, the less it has been inclined to acknowledge any intellectual debt to the Bible. Thus, the irruption of biblical text has been a turning point in Western cultural history, as it marks the change from a "symbolic form" (named "myth" by Cassirer) to another ("language"); moreover, the Pentateuchal text endeavour to bring out a new form of relationship with the time: that of history, neither cyclical nor yet prophetical, and which philosophy inherites without acknowledging its true debt. 
KEY WORDS: symbolic form, open history, critical hermeneutics, mythical narrative, philosophical debt.

Fecha de recepción: 20 de octubre de 2009

Fecha de aceptación: 3 de mayo de 2010 
Marc de Launay

Centre National de la Recherche Scientifique

Archivos Husserl de París, Francia

\section{Por una lectura filosófica del texto bíblico}

Traducción del francés de Silvana Rabinovich

Hoy, una lectura filosófica de la Biblia debe enumerar algunas consideraciones que la justifiquen, en la medida en que le es imposible disponer sin más del texto como de un fondo común propio de una tradición histórica. Tampoco le sería esencialmente provechosa la inversión brutal de la relación que por un tiempo estuvo en vigor — philosophia ancilla theologiae-, ya que por un lado la filosofía siempre querrá hacer valer una autonomía radical del pensamiento; y por otro lado, necesariamente se rehusará a meterse en un terreno donde sabe de antemano que se topará con un impasse en cuanto sea necesario enfrentar la cuestión del carácter sagrado del texto bíblico. La lectura filosófica no resolverá la delicada pregunta acerca del carácter inspirado del Pentateuco ni de la identidad "histórica" de su autor, menos aún la de su estatuto canónico o dogmático con respecto a los textos de la Nueva Alianza. Reivindicar una autonomía nos obliga a asumir un papel todavía más modesto que el inicialmente imaginado, porque la lectura filosófica nunca puede apoyarse en el presupuesto de que la llamada lumen naturale fuera la depositaria original del legado nada menos 
que "natural" y suficientemente especial para autorizar un uso trascendente de la razón. Así, la lectura filosófica se encomienda al principio a ser una crítica inmanente; pero de suyo no puede contentarse con comprender el texto tal como "sus" autores lo entendieron, sin dilucidar de entrada el problema de su atribución. Sin embargo, eso tampoco significa simplemente que impute los textos a autores humanos, que no fueron depositarios de una inspiración especial, sino más bien que estos habrán tenidoque satisfacer requisitos particulares, históricamente identificables, comparables al menos a los que nosotros mismos conocemos y despejamos en la lectura de otros textos antiguos. Desde este punto de vista, la lectura filosófica no podría pasar por alto los inmensos trabajos que desde hace dos milenios han escrutado estos textos, los han analizado, comentado, traducido, leído y releído hasta constituir una biblioteca que desde entonces escapa a toda aprehensión global. Pero los límites de la lectura inmanente entonces son obvios: ¿Cómo orientarse en esta masa de comentarios sin prejuzgar su valor? ¿Y según qué criterios de juicio se toma posición con respecto de aquello que esta crítica inmanente pone al día?

Cae por su propio peso que la lectura filosófica no puede verdaderamente adoptar tal o cual actitud apologética que obedecería inmediatamente a una confesión, ni contentarse con responder a una curiosidad historiadora, ni tampoco, como muy frecuentemente es el caso, convocar al texto bíblico citándolo al grado de un desarrollo para acomodar su gestión: nos extraviaríamos en un equívoco, ya que por un lado el texto bíblico sería solicitado en nombre de la autoridad que en general se le atribuye, para pronto, por otro lado, sólo reconocer esta autoridad a título de coadyuvante puntual. Además, la lectura filosófica no estaría motivada por un interés propiamente conceptual en la medida en que, precisamente, el texto bíblico no establece una red de conceptos que podríamos hacer valer frente a los de los sistemas. La lectura filosófica se orientará con más gusto 
hacia una vía que le es inmediatamente más familiar, la de una comparación de aquellos métodos a los que obedecieron los comentarios en función de las diferentes concepciones que, en el segundo plano, regían esta manera de abordar las Escrituras. El agregar a la crítica inmanente aquella, exterior, de las nociones esenciales de sentido y de tiempo tales como fueron implicadas por los diferentes modelos de interpretación parece complicar la tarea, imponiéndole un aumento de trabajo. En realidad es a la inversa, ya que solo una toma de posición actual sobre nuestra relación con dicha Antigüedad y, entonces, respecto de lo que creemos ver en ella de contemporáneo nos permite abordar tales textos, pero igualmente nos informa acerca de nuestra relación con la articulación entre el sentido y el tiempo; dicho de otro modo, respecto a la manera en que imputamos su fuente al sentido. Por supuesto, la lectura filosófica no puede arreglárselas sin filología, es decir, tanto nos lo revela el comparatismo histórico-cultural como una hermenéutica material, ya que de ella obtendremos finalmente algunas luces acerca de cómo nos parece que el texto mismo se organiza. La pregunta involucra directamente a otra sobre la deuda que la lectura filosófica debe admitir, al menos a título de hipótesis, con respecto a la Biblia. Formulada en otros términos, se vuelve a preguntar si acaso el Antiguo Testamento no se halla, en la historia general de la cultura, en el origen de una dimensión de esta última que la filosofía no habría forjado necesariamente. La lectura filosófica de la Biblia tiene pues, por justificación inicial, la hipótesis de que ella tendrá algo para aprender de sus interpretaciones y que solo podrá aprehender a partir de una reflexión de orden metodológico, es decir de orden formal, cuya validez, en consecuencia, no se vuelve obsoleta tan pronto como se cambia de corpus literario. Así, el interés de esta lectura es doble: al hacer de algún modo un desvío a través de textos que son por naturaleza exteriores a su tradición, la filosofía encuentra intereses que le son inherentes y cuyos efectos 
son llamados a modificar hasta la relación que ella mantiene con sus propios textos.

El interés por una lectura de textos considerados exteriores a la "filosofía" en su forma tradicional, es decir, sistemática, obliga a considerar y también indudablemente a reevaluar estas fuentes "exteriores": la tragedia, los relatos míticos cuando son organizados en mito-logía (es el caso notable de la Teogonía de Hesíodo), las tragedias griegas; pero, más en general, la poesía y la literatura. Una primera razón es que dichos textos han tratado temas que aparentemente son propios de la filosofía pero, en tanto tales, también son preguntas abordadas de otro modo, y sobre todo, a través de otras prácticas discursivas. Una segunda razón: el tratamiento discursivo diferente también puede ser abordado desde un punto de vista filosófico a condición de que la filosofía tome en cuenta no solamente una "razón extranjera" (Kant) que funciona en estas prácticas sino también su propia limitación discursiva: aquello que escapa al concepto stricto sensu, permaneciendo metafórico, no es en menor medida un motor filosófico. La noción de "mundo", la de "vida", por ejemplo, nunca son reductibles a conceptos; en cambio, estas nociones no dejan de ser aquello hacia donde tiende la conceptualidad filosófica sin, por el momento, ofrecer una resolución conceptual satisfactoria. Entonces, el trabajo del discurso filosófico no puede renegar de una de sus fuentes motoras ni rehusarse a recibir de ella, más allá del simple estímulo, iluminaciones provenientes de la poesía, de la literatura, etc. Una lectura filosófica de la Biblia hace resaltar la manera en que antes de la aparición de una tradición "filosófica" un texto trata acerca de su relación con los relatos míticos, esforzándose en desmontarlos al utilizar únicamente instrumentos textuales. Se trata de mostrar cómo una "forma simbólica" ( $c f r$. Cassirer), en este caso el "mito", encaja en una dialéctica que la subvierte a partir de medios tomados únicamente de esta forma en provecho de otra forma (la "religión"), en otras palabras, cómo un 
texto como el Génesis vuelve contra ellos mismos elementos míticos tomados de relatos anteriores o contemporáneos. La manera en que se efectúa esta vuelta y este desmontaje implica esencialmente la posibilidad de un retorno reflexivo sobre elementos textuales, haciéndolos variar al recomponerlos; el procedimiento reflexivo en sí mismo es de orden filosófico, en el plano formal, incluso si los elementos sobre los que se efectúa no lo son. El estudio que realizo intenta verificar sobre un texto preciso (Génesis 1 y 2) la presencia y la validez de este procedimiento, cronológicamente pre-filosófico, pero desde un punto de vista formal plenamente filosófico porque en lo que sigue va a inspirar a la filosofía.

\section{Reconocimiento de deuda versus negación de la finitud}

Pero, de manera más profunda, la lectura filosófica debe reconocer una deuda con respecto a la Biblia. Eso presupone que, desde el punto de vista filosófico, sería totalmente "bueno", como lo escribe Kant, "tener" una creencia religiosa, cuya obligación compartiríamos con otros, es decir, tener una creencia confesional. “Tener” una religión es, según él, una obligación moral del hombre para consigo mismo (Kant, La métaphysique des mours, VI, 443 ss.) porque el hombre —en la medida en que no es un ser puramente racional sino, al igual que sus fines y objetivos, en cierto modo está condicionado de la misma forma por el registro sensible - nunca está en todo momento y perfectamente en la "situación" en que podría obedecer al imperativo de la Razón pura: actuar solo en función de máximas subjetivas de la acción tales como pudieran, "en todo momento y simultáneamente", ser comprendidas como leyes universales. Así leeremos, en El conflicto de las facultades (Sección 1, 1, Observación general): "La Biblia alberga dentro de sí un testimonio de su divinidad (moral) que resulta suficiente desde 
un punto de vista práctico, [...] La divinidad de su contenido moral resarce cumplidamente a la razón de la naturaleza humana del relato histórico" (Kant, El conflicto, 133-134).

Inmediatamente notaremos que la apreciación negativa del "relato histórico" apenas enmascara el hecho de que a través del rodeo de una interpretación necesariamente histórica del relato se llega a desligar "lo que tiene de divino su contenido moral". Esto justifica de inmediato la apreciación lógicamente estética lato sensu del texto y el reconocimiento de su papel mediador en la transmisión del contenido de la Revelación. Pero eso no implica en nada que el estatuto de medio del texto afecte su contenido al cargarle las mismas limitaciones que las que gravan a todo relato hecho por hombres, en una época y en una lengua determinadas. El reconocimiento de una deuda con la Biblia, entendida como una de las expresiones de lo que debemos admitir a título de una "razón extranjera", obedece también a un interés filosófico: todo pensamiento crítico renuncia de entrada a la ambición de fundarse sobre cualquier certeza asentada en la aprehensión o la intuición de la omnitudo rerum, o, para decirlo en términos leibnizianos, la "mónada de las mónadas". Al mismo tiempo, la filosofía así orientada, abandona el terreno de la ontología, y renuncia a la pretensión de determinar qué es el ente, qué es el ser; ella renuncia a la ambición de ocupar, aunque sea subrepticiamente, la posición predicativa que le permitiría enunciar juicios sobre la totalidad. Esta ambición, por lo demás, ha conducido efectivamente a ciertos filósofos modernos, cuando no quisieron renunciar a ella, a volverse profetas. Este es, como se sabe, el caso de Nietzsche: "soy un vidente, pero despiadado; mi conciencia sigue a mi visión, yo soy pues el intérprete de mis visiones" ("Fragments posthumes", 453).

También a la vez afirma que su pensamiento divide en dos la historia, puesto que inaugura una nueva era (Ecce Homo, $\S 8$ ), y que de ahora en más debe reinar el amor fati, que lógi- 
camente no sabría hacerle lugar a cualquier innovación creadora, sino que deja subsistir solamente una "libertad" de tipo spinozista. La ironía quiere, sin embargo, que él no escape a la historia y que la redacción del "desángel” Así habló Zaratustra se inscriba en la prolongación de la ambición propiamente romántica de un Friedrich Schlegel, quien procura escribir una nueva Biblia: "el objetivo de mis proyectos literarios es escribir una nueva Biblia, y de caminar tras las huellas de Mahoma y de Lutero" (Schlegel, Briefe, carta 106, 183-184). ${ }^{1}$

El reconocimiento de la deuda se opone a la negación de la finitud en la medida en que si la tradición filosófica se imagina que no debe nada a lo que la precede ni a otras prácticas discursivas, tendría que poder demostrar que el sistema puede estar efectivamente acabado sin ningún aporte exterior heterogéneo. Entonces se plantea la pregunta para saber en qué medida los sistemas filosóficos se sucederían completándose como las teorías científicas, aunque su dimensión histórica fuese finalmente contingente. Como es sabido, la ambición cartesiana, leibniziana o incluso husserliana nunca alcanzó sus fines, es decir, ofrecer una adecuación total entre la conceptualidad sistemática y las idealidades o los fenómenos que son los referentes de esta conceptualidad. Tanto como no puede desterrar todo resto de retórica de su práctica discursiva, la filosofía en su forma sistemática no logra evacuar la historicidad efectiva que la limita: todo sistema filosófico se ve obligado a volverse, en gran parte, una "concepción del mundo" que no puede hacer más que reconocer múltiples deudas contextuales e históricas. La negación de la finitud anima la ambición del sistema que normal y naturalmente quiere abarcar la totalidad de lo real; esta ambición es "legítima", pero nunca es realizable, salvo si se cree que el pensamiento y el lenguaje pudiesen entrar en una relación de adecuación absolutamente exacta (la

\footnotetext{
${ }^{1}$ Carta del 20 de octubre de 1798 a Novalis.
} 
otra posibilidad es imaginar que el "lenguaje" se expresaría a través del pensamiento y lo formaría al informarlo; sin embargo, esta posición plantea la pregunta lógica de la posición de enunciación - "profética" - de quien afirma una tesis semejante, ya que tiene que disponer de medios especiales para asentar la convicción de que el lenguaje le hizo así esta revelación, porque, normalmente, él no debería operar una vuelta reflexiva sobre lo que el "lenguaje" le dicta, excepto que admita que no se trata de una "revelación” de la que solo él dispone).

\section{Tentación gnóstica}

La deuda contraída por la filosofía con la Biblia concierne entonces a la noción de historia, ya que hemos podido observar los esfuerzos considerables desplegados por la filosofía en torno a la comprensión de esta dimensión - esto se vuelve particularmente sensible a partir de Vico — para dominar la historicidad en una red que se tornaría controlable. Y el reconocimiento de una deuda afecta de otro modo al pensamiento filosófico cuando se instala en una actitud "profética", como podría demostrarse en el ejemplo de Nietzsche, ya que ella corre aún el riesgo insidioso de deslizarse precisamente hacia una "filosofía" de la historia, es decir, hacia una forma de gnosticismo reactivado.

El Pentateuco (Génesis) crea e inventa una concepción de la historia que no existía antes ni tampoco en su medio textual contemporáneo. El relato de Gilgamesh no ofrece en ningún momento una vuelta reflexiva sobre sus propios elementos constituyentes; en cambio, el texto bíblico toma elementos del relato de Gilgamesh, incluso algunos términos asirio-babilonios, pero lo hace precisamente para que operen de manera opuesta a los usos que les eran propios en sus leyendas ( $c f r$. el relato bíblico del diluvio, que retoma y critica el de 
Gilgamesh). ${ }^{2}$ La filosofía griega no ha tratado la historia en ese sentido (el Timeo solo considera ciclos cósmicos en los que la intervención humana no tiene ninguna incidencia); los "historiadores" griegos solamente abrevan de la historia a través del filtro de una concepción cosmológica, incluso Tucídides que interpreta la guerra del Peloponeso a través de las categorías de lo mismo - lo seco, lo terrestre, Esparta-, y de lo otro - lo húmedo, lo marino, Atenas - es decir que retoma las categorías empleadas por Platón en el Timeo y el Critias a fin de pensar metafóricamente los rodeos de lo mismo a través de lo otro, para finalmente volver a sí mismo. No pensar la historia como: a) hecha para los hombres, b) imprevisible, conduce a querer: a) profetizar (decir aquello que necesariamente acontecerá dado lo que ya se ha producido - ilusión reconstructora del pasado en función de categorías previas que no han resultado de interpretación); o a b) proponer un esquema "gnóstico" del curso de la historia, es decir, una misma estructura que se encuentra entre pensadores muy diferentes desde que emprenden una "filosofía sistemática" de la historia. Esta estructura ofrece siempre los mismos elementos: 1) disociación inicial en el seno de lo que es considerado como pleroma; 2 ) "caída" provocada por el principio negativo; 3) alienación al mundo considerado como prisión; 4) redención al término de una "catástrofe", poco importa su naturaleza (mesianismo de ruptura, revolución, reino del anticristo, etc.). Si pasamos revista a las diferentes concepciones filosóficas de la historia nos daremos cuenta de que solo los pensadores que aceptan que su sistema mismo sea sometido a la historicidad y entonces, limitado por una dimensión temporal y metafórica irreductible, son aquellos que reflexionan sobre la historia sin dar de ella una reconstrucción "universal" o "profética" o "gnóstica" (citaré con gusto a

\footnotetext{
${ }^{2}$ No sigo adelante porque escribí un texto sobre este tema y formará un capítulo de mi próximo libro sobre la lectura filosófica de la Biblia.
} 
Rickert y Cassirer entre estos últimos). "La verdadera filosofía, [...] aquella que parte de la única, de la pura vida divina [...] de hecho sólo es alemana, es decir original" (Fichte, "Discours à la nation allemande", Werke, VII, 362). Y él mismo se percibía con gusto como una suerte de relevo divino:

Yo soy el verdadero fundador de una época nueva, la de la claridad [...]. Todos los otros quieren mecanizar, yo, quiero liberar $[\ldots]$ el contenido infinito de esta libertad, la tarea moral, permanece inaprehensible, la imagen de Dios, precisamente porque él es en absoluto inaprehensible y que sólo es posible vivirlo en las revelaciones de la historia ("Exkurse zur Staatslehre", Werke, VII, 580 ss.).

Entonces el contenido de la filosofía no es el producto resultante de la reflexión, sino más bien una suerte de revelación de la cual se beneficia el espíritu, que sabe de manera inmediata que su conciencia tiene un origen divino y que entonces está en condiciones de discernir, por experiencia directa, eso que en la historia constituye su tarea moral. Los Discursos a la nación alemana insisten sobre la idea de que la humanidad debe lograr, por una nueva creación, revestir una forma nueva que la regenerará por cuanto ella iba a la ruina. La humanidad debe ella misma ser aquello en que va a transformarse y que no es otra sino la que era en el origen: "La antigua religión, que mantenía separadas la existencia del espíritu y la vida divina debe ser enterrada con el tiempo antiguo" (VII, 298).

Este rechazo hacia la religión tradicional, aparejado con el del mundo considerado como tierra desolada de alienación, revela la proximidad de Fichte con temas gnósticos antiguos donde ya aparece bien la revuelta de la conciencia individual contra el fatum cósmico, el cual aspira a una liberación concebida siempre como exención con respecto al determinismo universal y a la tradición. El mundo es el verdadero mal, el saber que no es consciente ni de su vida ni de sí, que es "nulo, 
sufriente, desgraciado"; al contrario del sí mismo "que tiene la intuición y el saber de sî́" y que así entra en la felicidad, es decir, vive en Dios (Fichte, "Religionslehre", Werke, V, 406, 402). "Elévate hasta el punto de vista de la religión y todos los velos caen, el mundo y su principio mortal se borran, y la divinidad misma penetra de nuevo en ti" (V, 471). Fichte rechaza a la vez la idea de creación — ve en ella: "el error de toda falsa teoría de la religión, es el principio original del paganismo y del judaísmo" — 3 (V, 479), y la de una separación radical entre Dios y su creatura $^{4}$ (V, 533 ss.). Un Dios exterior a la conciencia, al pensamiento puro, no es más un Dios, y Fichte identifica pura y simplemente el saber con la existencia divina - "nosotros mismos somos, en la raíz más profunda, la existencia divina" — 5 (V, 448 ss.), que tiene como consecuencia directa y considerable que el pecado no tiene más consistencia ni realidad exterior, ya que Dios no podría pecar contra sí mismo, así como tampoco podría ser afectado por las malas acciones de los hombres (V, 490). Al llamar a la divinidad como el ser absolutamente indecible y al designarla mediante la metáfora de la luz, Fichte, sin saberlo, sigue el mismo camino que un texto gnóstico, el Apócrifo de Juan (Jonas, "Le système”, 262-271), en el cual la divinidad solo existe a través de su expresividad histórica, donde el hombre elegido solo escapa a la alienación mundana gracias al don del conocimiento comprendido como un acontecimiento escatológico cuya finalidad es hacer el retorno, del árbol del conocimiento al árbol de la vida (Grundzüge des gegenwärtigen Zeitalters, Werke, VII, 129).

${ }^{3}$ En total coherencia fichteana Natorp también rechazará, un siglo más tarde, la idea de un Dios creador; $c f r$. su carta a Scholz del 1 de abril de 1917: "Yo no reconozco, pues, ningún Dios creador porque ni Dios hace el mundo ni el mundo (o el yo) es algo fabricado. Pero Dios, y el mundo (o más bien el alma [...] deviene — este ser y este acto de devenir están necesariamente ligados el uno al otro".

4 "El desarrollo del ser y de la vida divinos está en él [el hombre ético-religioso], esta vida divina sólo podrá desarrollarse en él”.

5 "El pensamiento puro es él mismo la existencia divina". 
El miedo ante la alienación a lo extraño y al resto del mundo considerado como fundamentalmente malo, temor que justifica el dualismo espiritual que opone metafóricamente la luz a las sombras mundanas, es decir el dios fichteano y alemán al resto de la tradición cristiana y metafísica errónea, la crítica de toda tradición religiosa anterior y la negación de la doctrina de la creación en la cual el verdadero Dios no podría estar implicado, las consecuencias morales de esta negación en cuanto a la existencia ilusoria del pecado en aquellos que penetra la luz, la ambivalencia moral a la vez ascética (mediante el rodeo de una educación dictatorial) y libertina (en su negación de toda institución que no sea ante todo comunitaria, y en la voluntad de hacer desaparecer el Estado), la pulsión unitarista y la irrupción permanente de la eternidad bajo la forma de una negación del presente, la soteriología del saber (reservada a los iniciados, los verdaderos yo), las formas litúrgicas extrañas que serán aquellas de lo que Fichte llama la República de los alemanes en el siglo XXII, ${ }^{6}$ he aquí tantos rasgos acercando indiscutiblemente esta doctrina político-religiosa a lo que sabemos de estas corrientes gnósticas de los primeros siglos de la era común.

\section{La historia como "profetismo": Cohen y Cassirer}

A pesar de no abordar lo que constituiría otra vertiente de las relaciones entre sentido y tiempo en el seno del horizonte de las religiones, a saber las corrientes místicas, se debe registrar el hecho de que en el siglo xx algunos pensadores han reconocido la deuda contraída por la tradición filosófica con respecto a la Biblia precisamente en materia de historia. Claramente es

\footnotetext{
${ }^{6}$ Se trata, ni más ni menos, de un nuevo catecismo que, adoptando cierta postura profética, anticipa el porvenir de esta nueva religión alemana que obedece a un cristianismo por lo menos sometido a revisiones esenciales.
} 
el caso de Hermann Cohen y luego de aquel que desde varios aspectos fue su discípulo, Ernst Cassirer.

En su última obra, La religión de la razón desde las fuentes del judaísmo, Cohen atribuye la creación de la noción de historia al profetismo:

En la conciencia griega, la historia significa simplemente lo mismo que saber. Así, para los griegos la historia se orienta única y exclusivamente al pasado. El profeta, por el contrario, es un vidente, no un sabio. [...] Los profetas son los idealistas de la historia. Su poder visionario generó la concepción de la historia como el ser del futuro (cap. XIII, §57, 202).

El paso de la historia nacional a la universal tiene lugar porque interviene la idea de mesías, no bajo su aspecto guerrero o en la perspectiva de un retorno triunfal a Sion, sino como representante del sufrimiento, de la indigencia perpetua de la humanidad en su conjunto. Así, los profetas anuncian un futuro idealizado, la reconciliación de Israel con su Ley, al mismo tiempo que una reconciliación de la humanidad en general después de la erradicación de los ídolos y del fin de la miseria: "La providencia encuentra su culminación en el mesianismo, la providencia hecha historia" (cap. XIII, §61, 203).

Esta manera de forjar la noción de historia implica, por un lado, que su esencia sea de orden ético (cap. XIII, §63-64) y, por otro, que a través del mesianismo entendido de esta manera, se afirme la "luz de la teodicea".

Al mismo tiempo en que redactaba su último libro, sin haber podido terminarlo, Cohen había afirmado, en una conferencia pronunciada en Viena, en 1916, luego repetida cuando fue su última aparición pública, el 7 de enero de 1918, en Berlín: "Platón y los profetas son las dos fuentes más importantes de la cultura moderna” (“L'idéal social”, 306). 
A los ojos de los profetas, el conjunto de la realidad se reduce a su dimensión temporal, y con la noción de una infinidad del tiempo, ellos responden a la oposición entre "Jerusalén" y el resto de la tierra:

Por esto su ser no reconoce ningún descanso, por el contrario todo evoluciona, todo se transforma en un eterno surgimiento de lo nuevo. Por ello, ninguna potencia de la realidad los alcanza, incluso el Estado, su propio Estado, no los tiene prisioneros. Él debe ser destruido y sólo subsistirá "el resto de Israel", para que todos los pueblos, gracias a él, puedan rejuvenecer (325).

Cassirer también fue sensible al viraje que según él constituye la aparición del profetismo en la evolución de las concepciones del tiempo calcadas de la observación de los ciclos naturales. La exhortación de Jeremías 10:2 — "No aprendáis las costumbres de los paganos, ni os espantéis de las señales del cielo, de las cuales los paganos se espantan"- - hace eco en el hecho de que la revelación no tiene lugar "bajo esta forma del tiempo que nos ofrece la naturaleza en la alternancia y el retorno periódico de sus figuras"; además, "la voluntad divina no se ha dado ningún signo en la naturaleza, de tal forma que ésta pierde parte de su importancia a favor el pathos ético y religioso de los profetas" (Cassirer, Filosofía de las formas, 158).

Así desaparecen a la vez la totalidad del tiempo cósmico y astronómico y una nueva conciencia del tiempo identificada enteramente con "la conciencia del futuro" que se refiere a una historia de los hombres ya independientes de las "leyendas patriarcales". Evidentemente Cassirer no olvida entonces su deuda con el maestro "quien de todos los pensadores modernos es el que más profundamente ha sentido y con la mayor pureza ha renovado esta idea básica y originaria de la religión profética"; efectivamente Cohen ha entendido bien que el tiempo devenía 
futuro y futuro esencialmente (Cohen, La religión, cap. XIII, $\S 35) .^{7}$

\section{De los profetas al Génesis}

Pero los profetas son evidentemente un fenómeno más tardío en la evolución de la religión judía y, además, se ve mal que ellos hayan podido desarrollar semejante concepción del tiempo sin adosarse a pesar de todo a una tendencia anterior y sin duda más profundamente instalada. En este aspecto, es de notar que Cohen nunca haya tratado de arraigar en el Génesis, más allá del lugar notable que le asignó a Noé, ${ }^{8}$ esta tendencia innovadora. Él ha notado claramente que, al contrario del mito, el mesianismo estaba orientado hacia el porvenir; pero se detiene, por decirlo así, en la reconstrucción del monoteísmo que opera, sosteniéndose sobre la idea de que es un "milagro" (Cohen, $\mathrm{La}$ religión, cap. XIII, § 14). En la conclusión del capítulo dedicado a la Creación, Cohen escribe que, desde el punto de vista de la lógica, "la creación parece un milagro, y la razón pretende sublimar la anomalía del milagro en la normalidad del pensamiento" (cap. III, §15, 53).

No obstante, si, como escribe al final del capítulo IV, "la razón no comienza con la historia, sino, al contrario, la historia tiene que comenzar con la razón" (cap. IV, §20 64), el "milagro" no es menos grande por hacer de la Creación un sinónimo casi alegórico de la creación de la razón humana: "La creación del ser humano tiene que significar la creación de su razón" (cap. V, §3, 66). Entonces a la vez hay que afrontar el desafío lanzado de este modo - superar la anomalía del milagro y pensar si no la creación, al menos su relato en una perspectiva

\footnotetext{
${ }^{7}$ Cfr. igualmente Ensayo sobre el hombre [Essai sur l'homme, 84 y 156].

${ }^{8}$ Noé es considerado por Cohen ya como un mesías "puesto que es el representante ideal de la humanidad eterna" (La religión, cap. XIII, §33).
} 
racional - y seguir no al maestro, sino al discípulo, para pensar históricamente la aparición en la historia general de la noción de historia: Cassirer considera que esta aparece como el signo de una liberación del mito. En su concepción de las "formas simbólicas", admite una evolución que no ve en el surgimiento de cada nueva forma simbólica la caducidad de la "precedente", ya que la evolución se despliega por sedimentación sucesiva, aunque se desprenda una orientación de conjunto: la finalidad sigue siendo la aparición de la "ciencia" que, a pesar de no ser la terminación de la historia de las formas simbólicas, sin embargo es aquella a partir de la cual las precedentes se vuelven verdaderamente analizables.

Ciertamente, la "ciencia" como forma simbólica de la que somos contemporáneos no excluye el resurgimiento de la forma "mito" ni menos aún que perdure la forma "lenguaje"; ella no es en nada la forma simbólica última, sino que corresponde a otra evolución, la cual asegura el pasaje de una forma a otra, y que es un proceso creciente de substancialización. El paso del "mito" al "lenguaje" corresponde a una substancialización de la naturaleza; el pasaje a la ciencia está acompañado de una substancialización del lenguaje.

Puede comprenderse la desconfianza de Cohen con respecto de Génesis 1 en la medida en que adoptar un punto de vista "lógico" debería conducir, ya sea, en efecto, a concluir una "anomalía" milagrosa, o bien a considerar el texto como todavía cargado de supervivencias mitológicas. Pero en ambos casos, el presupuesto sobre su estatuto se revela inmediatamente: si consideramos que Génesis 1 depende de la cosmogonía - y representa varias categorías, solo sería porque de manifiesto las toma prestadas de las leyendas asirio-babilonias-, entonces a fuerza hay que tomar todas las distancias impuestas por los desarrollos difícilmente refutables de la ciencia moderna de la naturaleza: la astrofísica, la geología, la paleontología, etc. "Lógicamente", es imposible no admitir una concatenación cau- 
sal que garantice a la materia una perennidad, vedando toda creación ex nihilo; "lógicamente", el milagro no hace buenas migas con las leyes de la naturaleza. Este problema inextricable, que sumió a Maimónides en un aprieto, tampoco podría ser abordado sin incomodidad por Cohen, quien hace deslizar la pregunta hacia su concepción de la creación como creación de la Razón sin resolver finalmente el enredo inicial. Pero si la Creación es creación de la razón, entonces, esencialmente del hombre, la problemática del tiempo aparece de inmediato. Ahora bien, Cohen no la evita, ya que le confiere una importancia decisiva al séptimo día y porque él hace del shabat, en varias ocasiones y muy diferentes contextos, una característica esencial de la vida religiosa tanto como de la vida social en la cual el sentido litúrgico se vuelve igualmente el símbolo de otra concepción del trabajo y de una visión de la humanidad: ¿acaso Cohen no ha llegado a defender el shabat como "domingo de los pueblos civilizados"?? Sin embargo, una vez más es sintomático que Cohen no escrute de cerca el texto de Gén. 2:1-4, como lo hace en cambio, muy a menudo, cuando discute la traducción de Kautzsch, por ejemplo, a propósito del estatuto del "extranjero". ${ }^{10}$ Más allá de su importancia litúrgica y su significación simbólica, el shabat presenta, sin embargo, de entrada una relación notable con la temporalidad.

\section{Las temporalidades del séptimo día}

En efecto, "el cielo y la tierra, así como todo su cortejo" habrán sido acabados, y Dios “culmina en el séptimo día aquello que había hecho” (Gén. 2:1-2). La primera indicación de orden tem-

\footnotetext{
${ }^{9}$ Cohen, "Der Shabbat", 45-72. En La religión de la razón, Cohen califica el shabat como "la culminación de la Creación" al tiempo que ve en él "la quintaesencia de todos los mandamientos" (cap. XIX, trad. esp, 333).

${ }^{10}$ Cfr. especialmente La religión de la razón, cap. IX, § 20.
} 
poral provista por el texto es la presencia del determinativo delante del ordinal (hashevi'i), el cual entra en consonancia con la designación del sexto día dado que allí todavía, pero solo allí entre los otros días, figura el determinativo. Este último es el indicio puramente semiótico de la entrada en otra forma de "duración", ya que de ahora en adelante existe el ser humano, y los otros días, con él, se vuelven de alguna manera una medida referida al ritmo de su propia existencia, cada día no era más que este o aquel. El verbo empleado para designar la culminación divina de la creación contiene una raíz que connota directamente la realeza, e indica, pues, lo que puede tener de soberana la distancia tomada respecto a lo precedente. $\mathrm{Al}$ mismo tiempo, es una característica de la posición clásica del narrador respecto de su propio relato. Luego, el versículo continúa repitiendo exactamente la misma fórmula "en el séptimo día lo que había hecho" haciéndola preceder de otro verbo: ishebot, 'detuvo'. El término, tomado del asirio-babilónico shapattu o shabattu, entra en la lógica de una elección lexical que de una vez suscita un efecto de reconocimiento para contrabatir mejor la familiaridad así creada, revelando, por un uso diferente, toda la distancia tomada con respecto al contexto cultural del cual se tomó prestado. "Shabattu" designa al décimo quinto día del mes lunar, dedicado al dios de la luna Sin Nannaru; es un "día de descanso de la tierra", pero igualmente son designadas con el mismo término las escansiones hebdomadarias del mes con las relacionadas a diversas prohibiciones, ya que estos días se consideran desfavorables. Aparentemente Génesis 1 retomó este ritmo heptameral, neutralizándolo de muchas maneras. Primero, rompiendo la enumeración lógica de los siete días con el simple hecho de que el que debía haber sido el primero (yom rishon) no está designado por un ordinal, sino por un cardinal (ejad); luego, se ha dicho, dotando de determinativo solo a los dos últimos días contemporáneos del hombre. Además, los astros fueron creados en el cuarto día, entonces después de 
la luz y del cielo — que introduce una distancia notable con el realismo cosmogónico - tienen como primera finalidad, antes de "alumbrar la tierra" y de indicar los días y los años, la de permitir un calendario de las fiestas. Dado que esta mención de las fiestas solo puede tener lugar ex post, comprendemos que su determinación existía antes de la redacción del texto y que,consecuentemente, sus fechas dependen de una memoria histórica y no de una imitación de las regularidades astrales. Pero, sobre todo, este séptimo día ofrece una particularidad inmediata: se trata de un día, y sin embargo no se hizo mención, como al finalizar los seis primeros, de una mañana y de una tarde.

\section{“Bendición” y santificación}

De igual modo, el séptimo día presenta otra característica especial: es objeto de una "bendición” y, lo que es más, de una santificación divinas. La disposición material de los versículos 2:2 y 2:3 es igualmente singular, ya que estos dos versículos están compuestos por tres enunciados de siete palabras, en cuyo centro está ubicado el sintagma “el séptimo día." Los dos primeros enunciados se encuentran claramente situados en el registro del "hacer", es decir, uno de los dos verbos movilizados por la creación (la'asot y bara): "y el séptimo día acabó Dios Su obra que había hecho; y descansó en el día séptimo de toda Su obra que había efectuado"; solo el tercero, donde intervienen "bendición" y "creación", entremezcla el "hacer" y el "crear": "Y bendijo Dios el séptimo día y lo santificó porque en él descansó Dios de toda Su obra que había hecho crear". Así, "bendición" y "santificación" se ubican en el registro de aquello que está regido por el "crear" más que por el "hacer", es decir sobre la vertiente de la innovación, connotación ligada al verbo bara como podrá constatarse en los usos realizados en 
lo sucesivo (Ex. 34:10; Núm. 16:30). En Génesis 1, la "bendición" —que debe distinguirse de los juicios llevados por Dios al término de ciertos días, "vio Dios que era bueno"-, solo se dirige a seres vivos, es decir a los animales marinos, los volátiles que han sido creados (bara), y la pareja humana (única obra de la creación a la vez hecha y creada): los animales terrestres (que fueron solamente "hechos"), cuyo "crecimiento y la multiplicación" caen bajo el control humano y son excluidos. La bendición, pues, debe comprenderse como un envite a perseverar en su ser, al menos en extensión, mientras que el crecimiento y la multiplicación tienen por corolario inevitable no más simplemente el espacio, sino inevitablemente la temporalidad biológica. Por añadidura, la bendición se dirige a seres vivientes creados y no simplemente hechos.

En fin, la perseverancia en el ser puede ir hasta una conminación de otro orden que el biológico, ya que, dirigida a la pareja humana, la bendición toma un giro nomológico: "llenad la tierra y sometedla; y tened dominio sobre los peces del mar, y sobre las aves del cielo, y sobre todo animal que se mueve sobre la tierra" (Gén. 1:28). La santificación en sí constituye naturalmente una progresión respecto a la bendición, y entonces solo concierne a la duración de este séptimo día. Ya es extraño que una duración sea "bendecida"; es más sorprendente aún que se diga sagrada, es decir, distinguida de manera singular y puesta así aparte a pesar de todo parecido o analogía con aquello de lo que está separada. La duración del séptimo día, entonces, es tres veces especial: no es la duración de un verdadero día porque no está comprendida entre una mañana y una tarde (o, para respetar el orden del texto, no está ritmada por un crepúsculo y un alba); es bendecida y santificada. El hecho de que Dios se detenga en su tarea de creador no significa que él "descansara", o estuviera "inactivo", en cuanto el bendecir 
y el santificar son actos; indica más bien que se supone que él no interviene más en el orden natural. ${ }^{11}$

La comprensión de estos dos actos parece complicada porque conciernen a una duración que, por su parte, no es delimitada. Inmediatamente estaríamos tentados a interpretar la temporalidad especial de este séptimo día al recurrir a la noción de eternidad, como parece al principio invitarnos el hecho de que este séptimo día en apariencia solo concierne a Dios mismo. Ahora bien, el texto no emplea nunca en Génesis 1 el término que correspondería a esta idea. En efecto, es notable que este término solo aparezca en Génesis 4, cuando será decisivo prohibir de ahora en más el jardín del Edén a los hombres. Es decir, una vez que han comido el fruto del árbol del conocimiento, y porque de ese modo se lo apropiaron, el adam y su mujer podrían estar tentados de consumir del fruto del árbol de la vida. En ese momento, el texto introduce el término 'olam, que puede significar tanto "mundo" como "siempre". ${ }^{12}$ Génesis 1 ha evitado cuidadosamente este término al hablar solo del "mundo" bajo la forma de una dualidad eretz veshamaim, y Génesis 2:4-5 reutiliza este sintagma invirtiendo incluso el orden de los términos, no para mostrar su improbable equivalencia, sino, sin duda, para reforzar lo que significa su unidad, el mundo, independientemente de su orden de aparición en el desarrollo de la creación. ${ }^{13}$ La eternidad, entonces, no está en el orden del sépti-

${ }^{11}$ La continuación del texto invalida parcialmente esta afirmación, ya que la alianza con Noé implica el compromiso de lo divino de no confundir más los ciclos naturales (Gén. 8:22); igualmente, Núm. 16:30, donde el texto dice literalmente: "Dios crea una creación", es decir, crea una innovación (que generalmente se traduce como "hace un milagro") al hacer que la tierra se abra para tragar a los que siguieron a Qorah en su revuelta.

${ }^{12}$ Incluso puede ser una manera de designar a Dios, el- 'olam (Gén. 21:33), que, cuando es usada por Abraham en el contexto preciso en que lo hace no deja de tener consecuencias ( $c f r$. M. de Launay, "La 'faute' d'Abraham").

${ }^{13}$ Aquí se abre igualmente otra perspectiva de interpretación: el texto evita la connotación de eternidad que podría afectar a la noción de mundo, primero porque precisamente acaba de ser creado; luego, porque ese mundo no podría disfrutar de 
mo día, sino que es una duración sin tarde ni mañana, una continuidad temporal abierta e indefinida. Sin embargo, ella tiene un comienzo, ya que interviene después del sexto día, es decir, comienza con el hombre o, al menos, en relación directa con él. Ese inicio, en la vertiente de los asuntos humanos, corresponde a una detención de cierta forma de actividad (creadora) divina. El texto introduce, pues, cierta modalidad de la negación: la negación "de abstención", comparable a la ausencia de juicio emitido sobre el cielo (Gén. 1:8) y sobre el hombre. ${ }^{14}$ Claro que el texto de Génesis 1 se cuida bien de no comportar ninguna fórmula de negación sintáctica; esta forma directa de negación no interviene en Gén. 2:5, con el vínculo hecho entre la ausencia de lluvia y la de los vegetales, el hombre (adam), el trabajo y la tierra (adamah). Continuará en otro plano que no concierne más a la existencia o la no existencia de las cosas y de los seres, sino que abre a otra dimensión, prescriptiva, cuando Dios formulará su primera prohibición (Gén. 2:17). Sin embargo, la negación está presente a lo largo del texto bajo una forma no aparente, y que es la de una demarcación constante respecto a datos mitológicos identificables: Gén. 1 no es la exposición de una cosmogonía, sino más bien de una "axiogonía". ${ }^{15}$

\section{La inauguración de la historia-toldoth}

Para comprender el alcance de los tres primeros versículos de Gén. 2, y estar en condiciones de proponer una interpretación

una eternidad que no es manifiestamente más que un "atributo" divino (no se trata aún de la problemática más tardía que opondrá a los que defienden la creación ex nihilo con los partidarios de una eternidad de la materia, sino simplemente de una delimitación de las temporalidades).

${ }^{14}$ Gén. 1:31 no debe confundir: lo dicho "muy bueno" es todo lo que Dios ha hecho (entonces no el hombre, que ha sido hecho y creado) o el conjunto de la creación bajo la modalidad del "hacer".

${ }^{15}$ La interpretación de Génesis 1 desde esta perspectiva será desarrollada en un estudio que aparecerá ulteriormente. 
de la "bendición" y la "santificación" de la duración abierta del séptimo día, hay que dimensionar los dos siguientes: "Estas son las generaciones (toldoth) del cielo y de la tierra cuando fueron creados, en el día que el Señor Dios hizo tierra y cielo". El término "toldoth" es de entrada problemático, ya que significa "engendramientos" en el sentido de descendencia humana, y siempre será empleado en la continuación del texto en ese sentido, como lo manifiesta, por ejemplo, Gén. 5:1, "este es el libro de las generaciones de Adam (sefer toldoth, libro de los engendramientos de Adam, la exposición de su posteridad, la lista de sus hijos)". Ahora bien, "la tierra y el cielo" no fueron engendrados, como tampoco tienen verdaderamente "descendencia". Evidentemente se puede "sobre-traducir" este término haciéndole significar los "orígenes", pero entonces se opera una suerte de anacronismo contextual que precisamente hace perder a esta palabra su fuerza de ruptura: el denominador común de todas las mitologías es justamente que el mundo resulta, por un antropomorfismo bien comprensible, de un engendramiento divino. Toldoth, en lo que sigue, ha acabado por significar la historia, el relato. Además, es notable que la orientación temporal connotada por toldoth siempre es el futuro, incluso si su sentido "genealógico" autoriza por supuesto que se pueda remontar a la fuente de sus engendramientos: aquí no hay un engendramiento inicial, sino una "innovación”, una creación (bara). En segundo lugar, la aparición, en el mismo contexto, de un nuevo nombre dado a Dios no puede dejar de llamar la atención. Este nuevo nombre, doble, intervendrá en la continuación del relato cada vez que se abrirá una perspectiva de porvenir para los hombres en general, a lo largo de Gén. 2:3-4 — salvo, y la excepción es notable, cuando habla la serpiente, ya que a ella no le es ofrecido ningún porvenir (Gén. 3:1-5)—, y para Israel en particular: Noé maldice a Ham, condenándolo a la esclavitud, bendice a Shem, ancestro de Abraham, en nombre de Yahveh-Elohim, y a Jafet solamente en nombre de Elohim 
(Gén. 9: 25-27). También es de recordarse, en Ex. 3:14, que el nombre de Yahveh es "explicado" por un doble no consumado, que connota de alguna manera un futuro del porvenir. ${ }^{16}$

\section{Historicidad y ahistoricidad}

Génesis 2:1-4 (5) construye así un nuevo sentido del término toldoth, que aparece como la resolución de la oposición entre duración de un día y duración bendecida y santificada de un día sin mañana ni tarde. Por un lado, esta duración inaugura lo que es la historia humana en general, pero, por añadidura, introduce una modalidad de la temporalidad: la sacralidad. Ahora bien, esta santificación no remite más a la concepción mitológica, dominante en aquella época, para la cual el tiempo es engendrado, a veces él mismo divinizado (Chronos) y circular. ${ }^{17}$ Este nuevo sentido no es simplemente una innovación en el seno de la lengua hebrea de la época, sino un giro de toda la cultura, en el sentido de que corresponde a un primer esfuerzo por oponerse a la mitología por otras vías y otros medios que aquellos a los cuales la filosofía, más tarde, recurrirá. Ciertamente, la "santificación" de la duración no puede traducirse todavía en un léxico conceptual de tipo filosófico, pero la expresión de una doble dimensión temporal — duración histórica y temporalidad perenne - permite a la vez escribir la historia pensándola como tal, escribir relatos integrando en ellos la anticipación, es

${ }^{16}$ Gén. 5:26 dice muy claramente que se empieza a invocar el nombre de Yahveh desde que nace el nieto de Adam, Enosh, que será el ancestro de Abraham, entonces desde que este nacimiento asegura anticipadamente un primer porvenir de Israel.

${ }^{17}$ Cfr. Ferécides de Syros, Teogonía, Diels, frgt. 1: "Zeus, Cronos y Ctonia (Gaia) existieron siempre. El tiempo (Cronos) produjo de su propio semen al fuego, al viento (o aliento) y el agua". [N. del T.: para su traducción al español $c f r$. G.S. Kirk, J. E. Raven, M. Schofield, Los filósofos presocráticos. Historia crítica con selección de textos, versión española de Jesús García Fernández, Gredos, Madrid, 2008, 85). Cfr. Igualmente Platón, Timeo, 34 a y 37 d: el tiempo se mueve en círculo, que es la justa imitación de la eternidad. 
decir, disponiendo al menos de dos registros de enunciación: la duración narrativa no es ingenuamente "realista", construye sus efectos de verosimilitud sobre la base de una temporalidad pensada, "distinguida" de la otra, la del curso efectivo de los acontecimientos. A su manera, con medios estrictamente lingüísticos, el texto introduce el punto de vista reflexivo en el seno mismo de un relato y, de partida, esboza la condición de posibilidad de aquello que nosotros pensaremos a través de la noción de historia, que siempre tiene este "doble sentido de ser a la vez el objeto y la manifestación de este objeto" (Cohen, Ästhetik des reinen, 392). La santificación de la duración corresponde a lo que entendemos como ahistoricidad, y esta última debe ser introducida en ese momento del relato porque inmediatamente será cuestión de una primera prohibición: la norma ética reivindica la validez perenne, y un registro formal que es la condición de posibilidad. En efecto, el contenido de las normas puede con razón considerarse como histórico, pero esta historicidad nunca prejuzga la ahistoricidad de la crítica de los contenidos, ni la dotación de un contenido, el cumplimiento de un valor por tal o tal "bien" cultural, es decir, un acto del espíritu que obedece a una lógica reflexiva que decide sobre la historia heredada y por hacer.

Así como Gén. 1:4 introduce la luz (ni hecha ni creada) como principio general de separación, así como solo tres "separaciones" son nombradas por Dios (noche/día, cielo/ tierra), del mismo modo la santificación de la duración sin fin del séptimo día desempeña un papel de separación superlativa. Contrariamente al mito que hace derivar de la sacralidad del origen su separación profana/sagrada, las separaciones nombradas por Dios no son originales, sino que resultan de un acto de lenguaje de nominación; y Gén. 2: 1-4 (5) refuerza una orientación general del texto: por el sesgo del lenguaje, es decir, de un relato ordenado por la anticipación y que hay que descifrar, se deberá abandonar el modelo del cosmos en provecho de una escucha obe- 
diente de los textos. No se trata más ya de intentar escrutar la naturaleza creyendo que "un puro espíritu se acrecienta bajo la corteza de las piedras", nostalgia romántica del Nerval de los "Versos dorados", sino de escuchar lo que dicen textos cuyos relatos invitan a la reflexión sobre su propia forma lingüística. El lenguaje sustituye al mito. El "libro" se vuelve fuente de un sentido innovador, que desempeña incluso conscientemente el papel de acontecimiento en la historia, anticipando sobre su porvenir, y deja de ser el registro de las crónicas del pasado.

Así, el profetismo se alumbra de un segundo plano del que toma sus convicciones, y las interpretaciones de Cohen, así como las de Cassirer, habrían debido arriesgarse a reconocer esta deuda eminente contraída por la filosofía con la Biblia. Cuando Jeremías (10:2) exclama: "No aprendáis las costumbres de los paganos, ni os espantéis de las señales del cielo, de las cuales los paganos se espantan", no se basa en las lecciones de Gén. 1 y 2 : 1-4, es decir, en la confianza de que hay un orden en la creación en el cual Dios se ha detenido de crear y de hacer; del mismo modo, y ahora más netamente, Isaías (43:18) reclama que se dé la espalda a la concepción tradicional de la temporalidad que, con la mitología, solo ve el bien supremo en el origen: "Mas no os acordéis de las cosas anteriores, ni consideréis las cosas antiguas". En otras palabras, vuélvanse hacia el porvenir y sean actores de y en la historia, ya que ningún acceso al espejismo de la eternidad es accesible, excepto el hecho de participar de una temporalidad especial: la del séptimo día de la cual todos los hombres, desde entonces, son contemporáneos.

\section{REFERENCIAS}

Cassirer, Ernst, Filosofía de las formas simbólicas, t. 2, trad. Armando Morones, México, Fondo de Cultura Económica, 1979 [La philosophie des formes symboliques, vol. 2, trad. fr. J. Lacoste, Paris, Minuit, 1972]. 
__, Essai sur l'homme, trad. fr. Norbert Massa, Paris, Minuit, 1935.

CoHen, Hermann, "Der Shabbat in seiner kulturgeschichtichen Bedeutung" [1869], en Jüdische Schriften, vol. II, Berlin, Schwetschke, 1924, 45-72.

_- "L'idéal social de Platon et des prophètes", en Jüdische Schriften, vol. I, Berlin, Schwetschke, 1924.

__, Ästhetik des reinen Gefuihls [1912], Werke, vol. VIII, Hildesheim, Olms, 1982.

—_, La religión de la razón desde las fuentes del judaísmo, trad. Andrés Ancona, Barcelona, Anthropos, 2004 [Religion de la Raison [1918], trad. A. Lagny y M. de Launay, Paris, Presses Universitaires de France, 1994].

Fichte, Johann Gottlieb, Grundzüge des gegenwärtigen Zeitalters [1806], Werke, VII, Berlin, De Gruyter.

—, "Exkurse zur Staatslehre" [1813], en Werke, VII, Berlin, De Gruyter, 1971 [reprod. de la edición del hijo de Fichte publicada en Berlín en 1845-1846].

_, "Religionslehre" [1806], en Werke, V, Berlin, De Gruyter, 1971.

JonAs, Hans, "Le système de l'Apocryphon de Jean", en La Religion gnostique [1958], trad. L. Évard, Paris, Flammarion, 1978, 262271.

KANT, Emmanuel, La métaphysique des mours, Ak. VI.

—, El conflicto de las facultades, trad. Roberto R. Aramayo, Madrid, Alianza, 2003.

Launay, Marc de, "La 'faute' d'Abraham", en Lectures philosophiques de la Bible, Paris, Hermann, 2007.

NiETZsChe, Friedrich, "Fragments posthumes Z I 4, 13 [1], été 1883" [Kritische Gesamtausgabe, vol. VII/1, Berlin, De Gruyter, 1977].

__, Ecce Homo: cómo se llega a ser lo que se es, trad. Andrés Sánchez Pascual, Madrid, Alianza, 1998.

Platón, Diálogos. Timeo, vol. VI, Madrid, Gredos, 2003. 
SHLEGEL, Friedrich, Kritische Friedrich-Schlegel-Ausgabe, F. Schöningh, Section III, "Briefe von und an Friederich und Dorothea Schlegel”, vol. 24, Paderborn, München 1980-1987. 